separately under the title Current Medical Research, and this year's issue (H.M.S.O., 1961. 4s. net) will be a valuable addition to any medical or biological library. It deals with: the viruses of the common cold; the causation of chronic bronchitis; a changing outlook on the surgical treatment of duodenal ulcer; auto-immune reactions and disease; the skin: normal and abnormal reactions in relation to disease; the pathogenesis and treatment of glaucoma; schistosomiasis : culture of parasitic flukes in the laboratory; the applications of fluorescence microscopy (illustrated); energy expenditure in man (illustrated); and physiological research in epilepsy. All these summaries of research are accompanied by references to some of the literature on each of these subjects.

G. LAPAGE

\title{
SCIENTIFIC RESEARCH AND DEVELOPMENT BY FOUNDATIONS AND HEALTH AGENCIES IN THE UNITED STATES
}

\begin{abstract}
A
SURVEY of Nonprofit Organizations-Expenditures and Manpower, 1957*, made by the National Science Foundation, estimates total expenditure in 1957 on scientific reserrch and development by foundations and health agencies in the United States at 94.6 million dollars, of which 71.5 million dollars came from the foundations. Educational institutions received 56.1 million dollars and nonprofit research institutes 6.5 million dollars. About 54.8 million dollars was for research and development in the biological sciences, and of the 1,000 scientists and engineers employed, more than 600 were engaged in research and development. Private foundations spent 71.5 million dollars either in research grants to others or in execution of research and development projects, two-thirds of the total being widely distributed among the biological, physical and social sciences in support of basic research, and some 12 of the 438 foundations provided $\mathbf{3 6 \cdot 7}$ million dollars. Expenditure by private foundations on their own research was only 12.7 million dollars, but they employed 892 scientists and engineers, of whom 593 were engaged in conducting or administering these research and development programmes and 200 were ongaged in the biological sciences.

Twenty-five voluntary health agencies reported expenditure on research and development, four accounting for 84 per cent of the total expenditure, which was almost entirely in the biological sciences, and 91 scientists and engineers were employed, 24 in research or development. Independent non-profit

* National Science Foundation. NSF-61-37: Scientific Research and Development of Nonprofit Organizations-Expenditures and Manpower 1957. Pp. vii +58. (Washington, D.C.: Government Printing Office, 1961.) 45 cents.
\end{abstract}

research institutions expended 89.9 million dollars on research and development, 36 per cent being on basic research and 80 per cent in the physical sciences. Of the 4,111 scientists and engineers employed, 4,046 were engaged in research and development, 40 per cent of them being physical scientists. Almost 30 per cent of this expenditure on research and development came from industrial contracts and 51 per cent from Federal contracts and grants.

The combined expenditure on research and develop. ment of the four Federal contract research centres was 25. I million dollars, more than four-fifths being in the physical sciences, 14.5 million dollars representing basic research. Of the 1,051 scientists and engineers employed, 1,045 were engaged in research and development. Of 131 professional and technical scientists covered by the survey, 49 either conducted or supported research and development, total expenditure for this purpose amounting to 6.7 million dollars, of which 4.7 million dollars was on that conducted by the societies themselves; slightly more than $\mathbf{1 . 2}$ million dollars went to educational institutions, 56 per cent of the expenditure represented basic research, mostly in the biological sciences. The societies employed 736 engineers and scientists, 451 being full-time but only 204 were engaged in research and development; physical scientists far outnumber the others.

Science museums, zoological and botanical gardens and arboretums, totalling 23 organizations, together expended 1.8 million dollars on research and development, some 80 per cent being for basic research, mostly in the life sciences and conducted within the organizations themselves, who employed 264 scientists and engineers, 142 being full-time workers.

\section{RESEARCH IN ANTARCTICA}

HEE five years from 1956 to 1961 have seen
nations, men and money involved in research
in Antarctica on an unprecedented scale, and the
rewards of new knowledge gained have accumulated
rapidly. The kind of investigations and the results
obtained have been described by Dr. G. De Q. Robin,
director of the Scott Polar Research Institute,
Cambridge, in a recent issue of ICSU Review (3, No. 4;
Ootober 1961).
The scale of effort made on research in Antarctica
is illustrated by the fact that nine wintering stations
were established in inland regions during one or both
of the years of the International Geophysical Year,
compared with the previous total of one man who had
spent one winter a short distance in from the coast.
Extensive oversnow traverses and aircraft flights have now sighted the major part of the $12,000,000$ $\mathrm{km} .{ }^{2}$ of the continent and surrounding ice-shelves. Only one major gap remains to be seen, namely an area of more than $1,000,000 \mathrm{~km} .{ }^{2}$ between the South Pole and the coastline of Antarctica between the meridians of $20^{\prime}$ west and $60^{\prime}$ east. Elsewhere, explorers have at least an approximate idea of the surface contours of the vast ice sheet covering this continent. A rough idea of the form of the rock surface beneath the ice has been obtained. Much has been learned about the climate of the continent, both at the surface and in the high atmosphere, while at still greater heights knowledge of the aurora and the ionosphere over Antarctica has been greatly 